\title{
JOHANN JACOB LEWERER
}

LIED (1828)

Auf einem zeitgenössischen Einblattdruck ist neben einer Skizze der wenigen über Kaspar Hauser bekannten Momente ein Lied J.J. Lewerers, Volksdichter aus Zirndorf bei Nürnberg, erhalten. Darin wird bereits früh die christlich-pädagogische Integration des Findlings angemahnt. Es ist auf die Melodie von $\mathrm{O}$ Gott, du frommer Gott $z u$ singen und wird mit einer ebenfalls sechsstrophigen Fürbitte beschlossen. [21]

\section{Lied}

1. Wie glücklich ist der Mensch wenn er in früher Jugend, Zur Thätigkeit, zum Fleiß, zur Gottesfurcht und Tugend Früh angewiesen wird, durch Eltern und durch Freund, Oder auch fremde Leut, wer es gut mit ihm meint.

2. Hingegen wenn ein Kind, von Menschen bleibt entfernet, Und nie die Muttersprach noch andre Sachen lernet, Wie viele Müh und Fleiß muß man nicht wenden dran, Bis ein Kind sprechen lernt und was begreifen kann.

3. Wie erst nach Nürnberg kürzlich ein junger Mensch gekommen, Um den die Obrigkeit vor All'n sich angenommen, Wer ihm durch Geistes-Bildung und Wohlthun Freud' macht hier, Bekommt vor Gott gewieß auch großen Lohn dafür.

4. Drum sey als Mensch und Christ, ihm jedermann gewogen, Und danke Gott, daß er wurd' christlich auferzogen, Ein jeder trage bei, daß der jung Mensch als Mann, Was lernt und einst als Christ, auch selig sterben kann.

5. Wenn dieser junge Mensch, lernt Lesen, Rechnen, Schreiben, Wenn er einst eine Kunst oder Handwerk würde treiben, Wenn er einst durch die Tauf und heiligen Abendmahl, Auch aufgenommen wird, zur wahren Christenzahl.

6. O wie wird sich sein Herz, Geist und Gemüthe freuen, Das Gott ihm so viel Gnad durch Menschen thät verleihen, O Vater, Mutter - wenn ihr noch am Leben seyd, Ich bitt euch macht euch doch theilhaftig solcher Freud, So wirds euch wohlgeh'n hier und dort in Ewigkeit! 